\title{
Benign Adrenal Gland Neoplasm
}

National Cancer Institute

\section{Source}

National Cancer Institute. Benign Adrenal Gland Neoplasm. NCI Thesaurus. Code C3629.

A non-metastasizing neoplasm arising from the adrenal gland. 